\title{
Polycyclic aromatic hydrocarbons degradation by composting in a soot-contaminated alkaline soil
}

\author{
L.M. Moretto $^{\text {a }}$, S. Silvestri ${ }^{b}$, P. Ugo ${ }^{a, *}$, G. Zorzi $^{\text {b }}$, \\ F. Abbondanzi ${ }^{\mathrm{c}}$, C. Baiocchi ${ }^{\mathrm{d}}$, A. Iacondini ${ }^{\mathrm{c}}$ \\ ${ }^{a}$ Dipartimento di Chimica Fisica, Università Ca' Foscari di Venezia, Calle Larga, Santa Marta 2137, Venezia I-30123, Italy \\ ${ }^{\mathrm{b}}$ Istituto Agrario di San Michele all'Adige (IASMA), S. Michele all'Adige (TN) I-38010, Italy \\ ${ }^{\mathrm{c}}$ Centro Ricerche e Servizi Ambientali Fenice, Via C. Menotti, 5 Marina di Ravenna I-00168, Italy \\ d Dipartimento di Chimica Analitica, Università di Torino, Via P. Giuria 5, Torino I-10125, Italy
}

Received 28 January 2005; received in revised form 31 May 2005; accepted 15 June 2005

Available online 8 August 2005

\begin{abstract}
This study deals with the biodegradation of the polycyclic aromatic hydrocarbons (PAH)s present in a soil contaminated by soot waste, characterised by a total PAHs content in the $200 \mathrm{mg} \mathrm{kg}^{-1}$ range. A challenging characteristic of the waste soil treated was its high alkalinity, with a $\mathrm{pH}$ of about 12.8 . The waste came from a soot-contaminated area located in the industrial zone of Porto Marghera, Venice (Italy). The biodegradation process employed was the composting of the waste with sewage sludge and yard waste. The process was carried out on a pilot scale using a closed tank with forced aeration for a period of 60 days, followed by 70 days with natural aeration. The time evolution of the process was monitored by following the time change in the concentration of the 16 US-EPA PAHs, as well as temperature, pH, electrical conductivity, $\mathrm{C}$ and $\mathrm{N}$ contents. Also phytotoxicity parameters, such as the growth and respiration indexes, were monitored. An induction time of about 30 days was observed, which corresponded to the time required before observing a significant self-drop in the waste $\mathrm{pH}$ and an increase in mass temperature. Afterward, a progressive drop in the PAHs concentration was observed, up to reaching after 130 days an overall degradation percentage in the order of $68 \%$. The degradation was more effective on rather low molecular weight PAHs (2-4 rings).

(C) 2005 Elsevier B.V. All rights reserved.
\end{abstract}

Keywords: PAHs; Soot; Bioremediation; Composting; Alkaline waste

\section{Introduction}

Polycyclic aromatic hydrocarbons (PAHs) are widespread pollutants which can enter the environment as a result of the incomplete combustion of organic matter (e.g. carbon black, automobile exhausts, tobacco, coal and wood combustion) or from the spilling of mineral or tar oils which can pollute soil and water. Due to their hydrophobic nature, most PAHs bind to particles of soil and sediments, which makes them less available for biological uptake [1,2]. PAHs polluted sites are subject to remediation activities since these compounds constitute anyway, a serious risk to human health as a result

\footnotetext{
* Corresponding author. Fax: +39041 2348594.

E-mail address: ugo@unive.it (P. Ugo).
}

of their toxic, mutagenic and carcinogenic properties [3]; for these reasons the US Environment Agency (EPA) included 16 unsubstituted PAHs in the priority list of pollutants [4]. Regulatory objectives and priorities related to the clean up of PAHcontaminated soils change country by country. In the United Kingdom the action level is set to $500 \mathrm{mg} \mathrm{PAH} / \mathrm{kg}$ air-dried soil for land used for recreation and 10,000 mg PAH/kg airdried soil for land with a hard covering. The United Kingdom, as well as Italy, takes the view that land should be cleaned to make it fit for its intended use. By contrast, other countries such as the United States and the Netherlands adopt a multifunctional approach whereby land must be fit for any use [5]. According to Italian regulatory guidelines, the maximum PAHs content in soils is $10 \mathrm{mg} \mathrm{kg}^{-1}$ for residential use and $100 \mathrm{mg} \mathrm{kg}^{-1}$ for industrial or commercial use [6]. The present 
study originates from the requirement of finding proper remediation procedures for re-use of a waste land in the industrial area of Porto Marghera, near Venice, Italy, which is heavily contaminated by PAHs. The study area extends over 43 ha and is located on the west bank of the Southern Industrial Channel. It was originally a marshland filled, probably before 1970, with industrial wastes constituted mainly by sandwiched layers of residues from bauxite processing and soot, during the reclaiming of the so-called 2nd industrial zone [7]. In the sampling site, soot wastes occupy a layer which can extend from the surface up to a depth of 3-4 m. Deeper, there is a layer made by residues of bauxite used for aluminium production, of thickness greater than $1-1.5 \mathrm{~m}$.

Few scattered herbaceous plants (Saxifraga tridactylites, Daucus carota, Senecio Vulgare, Lolium sp.) grow wildly here and there on the upper soot layer, however their roots expand horizontally, never reaching a depth higher than $1-1.5 \mathrm{~cm}$. In neighbouring zones, the soot was covered by filling soil (clayey/sandy/gravellous soil) on which some shrubs, trees (Salix alba, Sambucus nigra) and reeds (Phragmites australis) grow. A challenging characteristic and a serious limiting factor for the selection of the right bioremediation strategy proved to be the high alkalinity of this contaminated soil, which is characterised by $\mathrm{pH}$ values between 12 and 13 .

Microbial degradation represents the major route suitable for the ecological recovery of PAH-contaminated sites [8-10], with better results obtained for the degradation of low molecular weight PAHs (2-4 rings) [2]. The refractory nature of some PAHs is related to their limited water solubility, to their diverse and complex structure and to the requirement of providing oxygen to start degradation [11].

Experiments of extensive biological degradation were performed in well-defined conditions by treating PAH-polluted soils in bench-scale stirred reactors (bioslurry reactors) $[4,12]$. In some case, the addition of "outer" micro-organisms has been considered a valuable tool for increasing the rate and extent of biodegradation of PAHs [3].

Among ex situ bioremediation techniques, the composting treatment was proved to be effective in the degradation of PAHs, with good percent of removal (>90\% in some cases) and treatment time shorter than landfarming [13-15]. Fungi possessing ligninolytic properties have been shown to be active in PAHs degradation [2,16] and, recently, the use of spent mushroom compost was used to demonstrate degradation of PAHs in soil samples spiked with known amounts of some PAHs [17]. The impact of composting strategies on the treatment in soils and waste contaminated with PAH was the subject of some recent reviews [5,18].

Environmental conditions which can affect the biodegradation rate are: high temperature which increases the rate of enzymatic reactions and water solubility as well, good availability of nutrients, high moisture level, good oxygenation, presence of alternative substrates required for fulfilling cooxidation reactions, increased microbial variety and $\mathrm{pH}$ near neutrality. The latter parameter is crucial to the treatment of the alkaline waste soil studied by us since it is known that large variations from neutrality conditions can inhibit any microbiological degradation [11].

The aim of the present work is to verify the applicability of a bioremediation process, such as composting, to the contaminated soil of the study area, in order to make possible its re-utilization for industrial or commercial activities. From a general viewpoint it can be noted that, even if composting has been already successfully applied to remediation of sootcontaminated soils [19-23], at the best of our knowledge no study was devoted to the use of such a strategy for remediation of PAH-polluted soils characterised by such extreme alkalinity as the one examined here.

\section{Materials and methods}

\subsection{Sampling}

The sampling site is located in Porto Marghera, Venezia, Italy, on the west bank of the Southern Industrial Channel and is known as " 43 ettari" since the waste extends over 43 ha. Previous preliminary studies pointed out a large compositional variability of PAHs concentrations in different zones of the study area. In the present work, sampling was carried out in a $2 \mathrm{~m} \times 2 \mathrm{~m}$ area which was singled out as "typical", since it contained a concentration of pollutants which can be considered as representative of the "average" PAHs concentration spread over the all 43 ha of the waste land. The upper layer of the sampling area up to $3 \mathrm{~cm}$ depth, turbed by wild plants roots and exposure to atmospheric events was discharged, while the lower layer (from 3 to $50 \mathrm{~cm}$ depth) was sampled and used for the experiments. It was collected with a shovel and deposited over a plastic sheet and homogenized directly in the field using small plastic shovels. Then, it was put in polyethylene terephtalate jars, hermetically sealed and labelled. The samples were immediately shipped to the composting centre. The total weight of the sample was approximately $200 \mathrm{~kg}$. The samples displayed the typical grey-black appearance of soot. At the sampling time (April 2001) the area was drenched with water from recent heavy rain precipitation. No further pre-treatment was performed.

\subsection{Pilot reactor design}

Fig. 1 presents a schematic drawing of the pilot reactor used. It was constituted by a closed tank $1.4 \mathrm{~m}$ long, $0.95 \mathrm{~m}$ wide and $1.4 \mathrm{~m}$ high, with a volume of $1.86 \mathrm{~m}^{3}$. The mixture to be treated was put over a grill present in the bottom part of the tank. A system of fans aerated the mass and sent the exhaust air to a biofilter before discharge in the atmosphere. A temperature probe connected to a data logger (DL) was inserted $(70 \mathrm{~cm}$ depth) to monitor the (inner) biomass temperature, while a manual temperature probe was used when sampling.

The mass to be treated was prepared by mixing $146 \mathrm{~kg}$ of soot (S) with $1029 \mathrm{~kg}$ of "active mass" (AM) in a mixing 


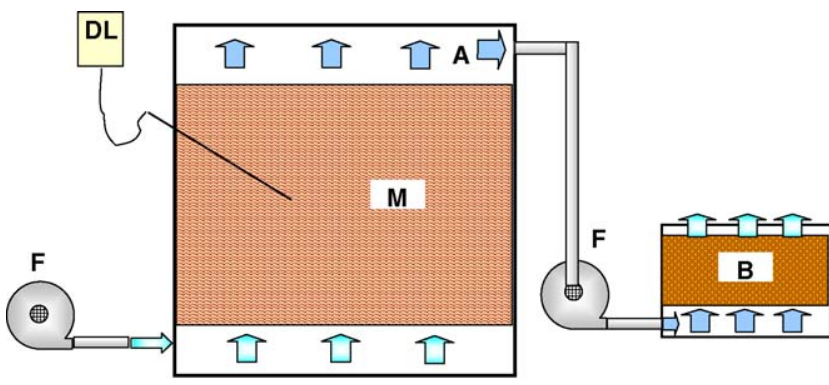

Fig. 1. Schematic drawing of the pilot reactor used for the composting process. F, fan; M, mass; DL, data logger; B, biofilter; A, air.

ratio of 1/2.5 S/AM (v/v) corresponding to 1/7.05 S/AM on a wet weight basis. The so-called "active mass" was a mixture of sewage sludge and yard waste $(1 / 2.5 \mathrm{v} / \mathrm{v})$ taken in the first phase of composting (15th day), thus presenting a very high biological activity. The mixture $S+A M$ was first homogenised by a mechanical shovel and than by a turning machine; in such operations emission of volatile compounds was noted. Warning: the use of protection masks when performing such mixing operations is recommended.

On the basis of the literature [24] and previous experience performed by some of the authors, the air flow required to oxygenate a mass containing $1 \mathrm{t}$ of volatile solids was estimated to be equal to $20 \mathrm{~m}^{3} \mathrm{~h}^{-1} \mathrm{t}^{-1}$. This was obtained by setting the fan ON/OFF with 15 min steps in order to achieve an effective average air flow of $7.5 \mathrm{~m}^{3} \mathrm{~h}^{-1}$.

The process was carried out for overall 130 days, the first 60 under forced aeration regime (see above), the other 70 days under natural aeration of the mass. Every 30 days the mass was turned by shovel, in order to better homogenise the biomass. At the same time, three samples (total mass of about $3 \mathrm{~kg}$ ) for the chemico-physical and biological analyses were collected. Intermediate sampling was possible by using a manual drill inserted in the mass at different points.

General characterisation of the samples mixed with compost was performed according to Italian regulations [25], and the specific analytical methods cited in Section 2.3.

The moisture content was checked frequently in order to avoid possible dehydration of the mass caused by the increase of the temperature. The composting mixture was amended with distilled water only at 30th day of the treatment. Afterwards, the moisture level kept within the optimum range for the biological process [26] and no other water addition was required.

\subsection{Analytical procedures}

Soil $\mathrm{pH}$ was measured with a glass electrode according to Italian Regulation for soils [6], using an aqueous suspension (1:5 soil:water); electrical conductivity (EC) was measured in the same filtered solution. Total organic carbon (TOC) content was determined by oxidation with $\mathrm{K}_{2} \mathrm{Cr}_{2} \mathrm{O}_{7}$, while the humic carbon content was measured by using $\mathrm{Na}_{4} \mathrm{P}_{2} \mathrm{O}_{7} \cdot 10 \mathrm{H}_{2} \mathrm{O}+\mathrm{NaOH}$. Total $\mathrm{N}$ was obtained by using standard Kjeldahl method. Moisture was determined by drying $200 \mathrm{~g}$ of the sample at $105^{\circ} \mathrm{C}$ for $12 \mathrm{~h}$ and measuring the weight loss. Ash content was determined on dried samples by a loss-on-ignition procedure in a muffle furnace held at $550^{\circ} \mathrm{C}$ for $4 \mathrm{~h}$ to burn the volatile solids (VS).

$\mathrm{pH}$ and temperature were measured every 5 days, while the other parameters $(\mathrm{C}, \mathrm{N}$, ash, $\mathrm{EC}$, etc.) were monitored in the raw soot sample, in the compost ready for mixing, in the $\mathrm{S}+\mathrm{AM}$ mixture soon after the mixing (time 0 ) and at days $30,45,60,90$ and 130 of the treatment.

Total heterotrophic microflora was determined by the Plate Count Method on R2A Agar (Difco) [27]. After growth, microbial diversity was qualitatively evaluated without any strain identification.

\subsection{PAH analysis}

PAHs concentrations were determined by gaschromatography/mass spectrometry (GC/MS), following the Method $3540 \mathrm{C}$ EPA. In detail, $10 \mathrm{~g}$ of sample were treated with $200 \mathrm{~mL}$ of dichloromethane in Soxhlet extractor for $5 \mathrm{~h}$; then $10 \mathrm{~mL}$ of the extract were evaporated to dryness, re-dissolved in $1 \mathrm{~mL} \mathrm{CH}_{2} \mathrm{Cl}_{2}$ and analysed by GC/MS.

Even after careful mixing of the overall sample, large variability was observed in PAHs concentration when different subsamples (about $10 \mathrm{~g}$ each) were analysed; however, the relative standard deviation within the same subsample remained small $(<10 \%)$. PAH analyses were carried out at time 0 and 30, 45, 60, 90 and 130 days. Duplicate analyses were performed for each sample, with an agreement between the two data of at least $10 \%$. The values given in the following are the average of these duplicates.

\subsection{Phytotoxicity and respirometric tests}

Phytotoxicity tests, i.e. germination index (GI) and growth index (also named production index, PI) were performed using Lepidium sativum as test plant [25]. For the germination index, the soil sample was added with water up to $85 \%$ of moisture; after $2 \mathrm{~h}$ the soil extract separated by centrifugation $(6000 \mathrm{rpm})$ and following filtration $(0.8 \mu \mathrm{m})$ was diluted with distilled water to volume ratio of $1: 1=$ extract:water and 3:1 = extract:water. Five milliliter of each dilution were distributed in five Petri dishes with 10 seeds each, and then incubated at $27^{\circ} \mathrm{C}$ for $24 \mathrm{~h}$ in the dark. The number of germinated seeds and root elongation for the sample and for the control (distilled water) were used to calculate the germination index according to the following equation:

$\mathrm{GI}(\%)=\frac{G_{\mathrm{s}} L_{\mathrm{s}}}{G_{\mathrm{c}} L_{\mathrm{c}}} \times 100$

where $G_{\mathrm{s}}$ and $G_{\mathrm{c}}$ are the average number of germinated seeds in the sample and in the control replicates, respectively, and 
$L_{\mathrm{S}}$ and $L_{\mathrm{C}}$ are the average root elongation in the sample and in the control replicates, respectively.

The growth index (PI) was obtained by a pot trial which required at least 20 days of growth in a greenhouse $\left(25^{\circ} \mathrm{C}\right)$. An amount of soil sample equivalent to 75 and $150 \mathrm{~g} \mathrm{~L}^{-1}$ of dry matter was added to a substrate made of $50 \%$ sand and $50 \%$ peat, using pots of $1 \mathrm{~L}$ capacity. Three replicates were prepared for each dose and sown with 100 seeds/dose. Three pots with the mixture sand and peat were used as control. The plants were cut after about 20 days, the grown vegetative biomass (as dry matter) was weighted and referred to the control. The final result expressed as growth index (PI, \%) is calculated as follows:

$\mathrm{PI}(\%)=\frac{P_{\mathrm{s}}}{P_{\mathrm{c}}} \times 100$

where $P_{\mathrm{s}}$ and $P_{\mathrm{c}}$ are the average biomass growth in the sample and in the control replicates, respectively.

The respiration assay (RI) was carried out at a constant temperature of $30^{\circ} \mathrm{C}$ by using a static tool [28] made of two stainless steel air-tight vessels (29 L each). $250 \mathrm{~g}$ of sample were put in each chamber together with $2 \mathrm{~N} \mathrm{NaOH}$ solution. A pressure probe is located on the cover to measure the depression inside the chamber due to the microbial $\mathrm{O}_{2}$ consumption and the $\mathrm{CO}_{2}$ absorption by the $\mathrm{NaOH}$ solution. After 72-96 h the respiration index (RI), expressed as mg $\mathrm{O}_{2}(\mathrm{~kg} \mathrm{VS})^{-1} \mathrm{~h}^{-1}$, was calculated both as maximum RI and $\mathrm{RI}_{24}$, i.e. the mean value obtained from the calculation on an integral average value on the $24 \mathrm{~h}$ of maximum $\mathrm{O}_{2}$ consumption.

\section{Results and discussion}

\subsection{Initial soil characterisation}

The measured $\mathrm{pH}$ of the studied soil is 12.8 , that is a very high value compared to ordinary soil $\mathrm{pH}$ values (6-8). The same consideration can be done for the EC value, which is equal to $7610 \mu \mathrm{S} \mathrm{cm}^{-1}$, indicating anomalous physical conditions of the soil. Organic carbon and total nitrogen contents were about 2.9 and 0.4 , respectively, giving a $\mathrm{C} / \mathrm{N}=9.7$. Other physico-chemical characteristics of the contaminated soil, together with those of the active mass used as amendment are presented in Table 1.

The $\mathrm{C} / \mathrm{N}$ ratio has a fundamental significance because nitrogen is necessary to support cellular synthesis and carbon makes up the largest fraction of organic molecules in the cell. During active aerobic metabolism, microbes use about 15-30 parts of carbon for each part of nitrogen, i.e.
$\mathrm{C} / \mathrm{N}=15-30$ [24]. Such values were achieved by the addition of the AM substrate to the $\mathrm{S}$, which increases the $\mathrm{C} / \mathrm{N}$ and produces a better balance between $\mathrm{C}$ and $\mathrm{N}$ for the microbial activity.

Total heterotrophic microflora of the soil was estimated to be about $10^{3}-10^{4} \mathrm{CFU} \mathrm{g}^{-1}$ (CFU, colony forming units), with a low significance, due to the poor growth on the culture medium. This was probably due to the very high $\mathrm{pH}$ value of the soil sample, which is very different from $\mathrm{pH}$ values typical of culture media (pH 6-8). Such a high $\mathrm{pH}$ creates difficulties both in soil microbial life, and, when using traditional cultivation techniques, for enumerating and selecting the total microflora. Another possible cause of the low CFU values can be the kind of contamination of the site; values of $10^{2}-10^{5} \mathrm{CFU} \mathrm{g}^{-1}$ were found in fact, in sites contaminated by tar oil [3]. Moreover, also the qualitative microbial variety was not very high (about five different strains), in comparison with the higher variety observed by us in other PAHs contaminated samples from different sites, but characterised by a soil $\mathrm{pH}$ of 6.5 .

As far as PAHs analyses are concerned, typical concentrations determined in the sample to be treated by composting, are listed in Table 2. This table reports data for both the 16US-EPA PAHs (upper 16 lines of the table), as well as for other PAHs. It shows that the total concentration of the USEPA PAHs is significantly higher than the concentration of not-US-EPA PAHs. The total PAHs concentration is in excess of $200 \mathrm{mg} / \mathrm{kg}$.

Not-US-EPA PAHs include methyl PAH derivatives, which are not combustion products, as well as some oxygenated derivatives (mainly with carbonyls groups) produced probably by oxidation of original PAHs by atmospheric oxygen. For simplicity, during the composting treatment the changes in concentration of the 16-US-EPA PAHs, plus that of benzo[ghi]fluoranthene, which is the most abundant nonUS-EPA PAH, were followed. Preliminary GC measurements showed that polychlorobiphenyls, dioxines and phenols, were below the limits of the Italian law and therefore they were not considered in the following part of this work.

\subsection{Evolution of the biological process}

Preliminary test in bioslurry reactors showed inhibition of the bioremediation process when operating at the natural $\mathrm{pH}$ of the suspension ( $\mathrm{pH}$ 12.8). On the other hand, attempts to lower the $\mathrm{pH}$ by controlled addition of sulphuric acid up to reaching a $\mathrm{pH} 7$ value and to restore the microbial activity re-inoculating the indigenous consortium, did not show significant improvements in PAH-degradation. Further studies on these aspects are in progress.

Table 1

Physico-chemical characteristics of the soot sample (S) and the active mass (AM) before the composting treatment

\begin{tabular}{llllllrrr}
\hline Sample & Time (days) & Moisture (\%) & Ash (\%d.m.) & \multicolumn{1}{c}{ pH } & EC $\left(\mu \mathrm{S} \mathrm{cm}^{-1}\right)$ & Org. C (\%d.m.) & Tot. N (\%d.m.) & C/N \\
\hline S & - & 56.7 & 92.4 & 12.53 & 7610 & 2.9 & 0.3 & 9.7 \\
AM & 15 & 57.8 & 30.2 & 8.06 & 1080 & 35.2 & 1.66 & 21.2 \\
\hline
\end{tabular}


Table 2

Screening concentration of 16 US-EPA PAHs and not included in the USEPA PAHs priority list found in a sample of soot-contaminated soil (fraction $<2 \mathrm{~mm}$ ), before treatment

\begin{tabular}{lll}
\hline & PAH & Conc. $\left(\mathrm{mg} \mathrm{kg}^{-1}\right.$ dry soil $)$ \\
\hline US-EPA & & \\
1 & Naphthalene & 14.3 \\
2 & Acenaphthylene & 2.70 \\
3 & Acenaphthene & 0.02 \\
4 & Fluorene & 0.39 \\
5 & Anthracene & 14.8 \\
6 & Phenanthrene & 11.4 \\
7 & Fluoranthene & 10.31 \\
8 & Pyrene & 69.6 \\
9 & Benzo[a]anthracene & nd \\
10 & Chrysene & 0.13 \\
11 & Benzo[b]fluoranthene & nd \\
12 & Benzo[k]fluoranthene & 18.7 \\
13 & Benzo[a]pyrene & 3.61 \\
14 & Dibenzo[a,h]anthracene & nd \\
15 & Indeno[1,2,3-cd]pyrene & 12.4 \\
16 & Benzo[ghi]perylene & 9.3 \\
& Total & 157.62 \\
Non-US-EPA & Biphenylene & 0.06 \\
& Phenalene & 0.14 \\
& 9,10-Phenanthrenedione & 0.55 \\
& Anthracene, 9-ethenyl-one & 0.05 \\
& 9H-fluoren-9-one & 2.62 \\
& 2-Phenylnaphtalene & 0.21 \\
& 3-Methylpyrene & 0.28 \\
& Benzo[ghi]fluoranthene & 55.94 \\
& 7H-Benz(de)anthracen-7-one & 0.67 \\
& Total & 60.52 \\
\hline
\end{tabular}

nd, not detectable.

A quite different situation was encountered during the composting treatment. Fig. 2 shows the time dependence of the biomass temperature measured at two different depths of the reactor (inner and surface biomass), the ambient air temperature and the $\mathrm{pH}$ of the treated mass. After an initial constancy of these parameters, the temperature started to rise up to reach maximum values between 40 and $55^{\circ} \mathrm{C}$ between days 25 th and 45 th. Concomitantly, progressive decrease in the $\mathrm{pH}$ was observed, this parameter reaching a value of $\mathrm{pH} 9.0$ at day 35 th and stabilizing between $\mathrm{pH} 8.0$ and 8.5 for a long time. It is known from the literature [5] that the optimum temperature for the degradation of PAH by composting is between 40 and $45^{\circ} \mathrm{C}$, which represents the overlap point of the optimal con-

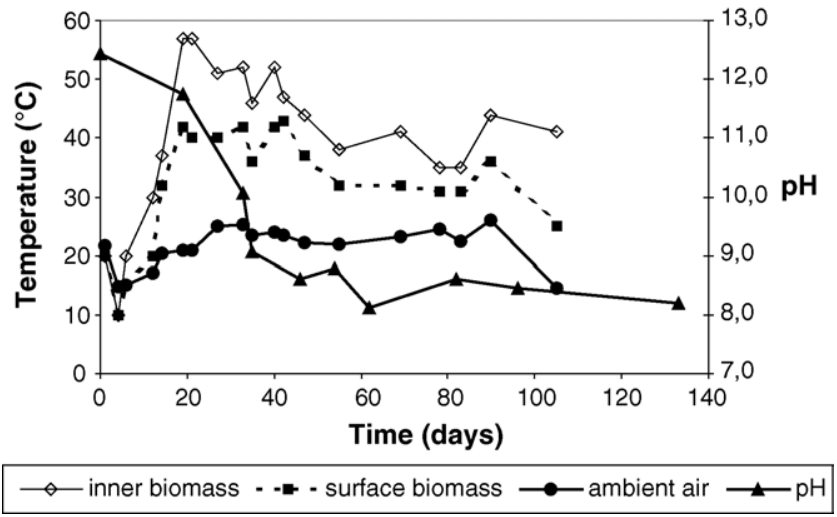

Fig. 2. Time dependence of temperature and $\mathrm{pH}$ during the composting process.

ditions for mesophylic and thermophylic micro-organisms. In our process slightly higher temperatures were produced when biodegradation started. This thermophylic phase continued up to the day 55th when the temperature sets at values between 35 and $44{ }^{\circ} \mathrm{C}$, remaining approximately constant during the following part of the process (mesophylic phase). Such a temperature profile indicates the achievement of an active aerobic microbial consortium. The parallel trend in the time evolution of $\mathrm{pH}$ and temperature confirms the key role of the former parameter for the bioremediation process. As shown in Table 3, also EC lowers significantly with the activation of the biological process (30 days), while a gradual mineralization of the organic matter can be gathered from the increase of the ash content, as well as the reduction of organic carbon and stabilizing of the nitrogen level (1.5\%).

\subsection{Evaluation of the biological quality of the substrate}

The first two lines of Table 4 report the phytotoxicity parameters measured in the raw soot and active mass; the following lines report the time evolution of the same parameters after mixing between $\mathrm{S}$ and $\mathrm{AM}$ and during the progress of the composting treatment. The germination index did not show significant trend of change between the initial soot sample and the composting treatment. This indicates that such a phytotoxicity test is unsuitable for highlighting the presence of polluting substances as PAHs, probably because of the low water solubility of these compounds; on the contrary, the

Table 3

Changes in some physico-chemical characteristics of the mass during the composting treatment

\begin{tabular}{|c|c|c|c|c|c|c|c|c|}
\hline Time (days) & Moisture (\%) & Ash (\%d.m.) & $\mathrm{pH}$ & $\mathrm{EC}\left(\mu \mathrm{S} \mathrm{cm}^{-1}\right)$ & Org. C (\%d.m.) & Humic C (\%d.m.) & Tot. N (\%d.m.) & $\mathrm{C} / \mathrm{N}$ \\
\hline 0 & 54.5 & 40.3 & 12.45 & 7370 & 30.4 & $\mathrm{~nm}$ & 1.22 & 24.9 \\
\hline 30 & 52.0 & 44.8 & 10.06 & 630 & 31.9 & 4.9 & 1.11 & 28.7 \\
\hline 45 & 53.4 & $\mathrm{~nm}$ & 8.61 & 850 & $\mathrm{~nm}$ & $\mathrm{~nm}$ & $\mathrm{~nm}$ & $\mathrm{~nm}$ \\
\hline 60 & 56.6 & 47.3 & 8.13 & 710 & 27.0 & 6.9 & 1.40 & 19.3 \\
\hline 90 & 51.7 & 53.3 & 8.45 & 760 & 21.1 & 8.2 & 1.49 & 14.2 \\
\hline 130 & 51.5 & 59.9 & 8.20 & 710 & 25.1 & 6.35 & 1.52 & 16.5 \\
\hline
\end{tabular}

$\mathrm{nm}$, not measured; time 0 gives the situation soon after the initial mixing. 
Table 4

Time evolution of phytotoxicity parameters and respiration index during the composting treatment

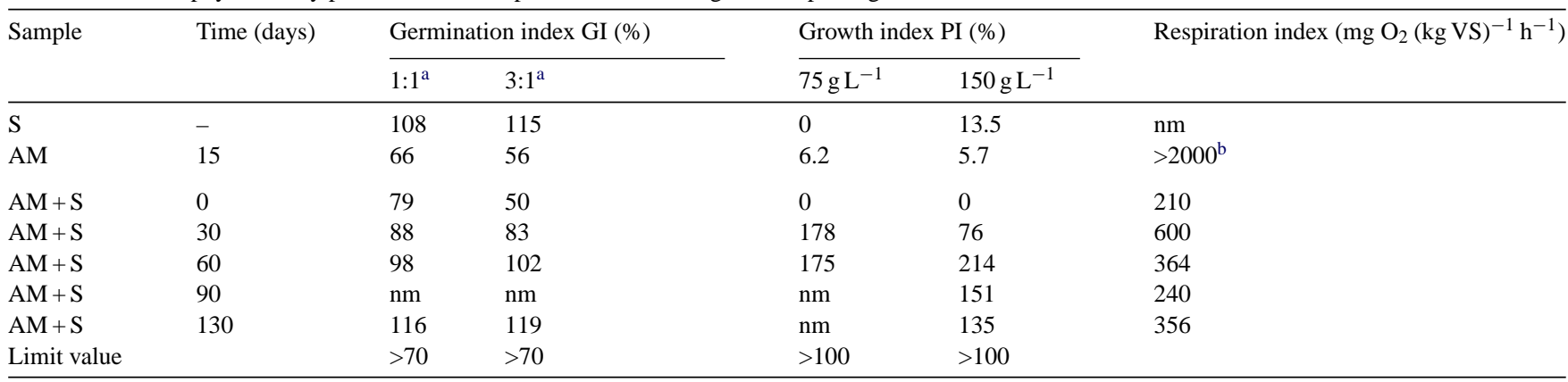

$\mathrm{S}$, raw soot; AM, active mass; nm, not measured.

a Extract diluted with distilled water at the indicated dilution ratios (see text).

b Mean value referred to the AM treated by the composting plant.

growth index shows strong changes all along the treatment. As shown by data in the first line of Table 4, the phytotoxicity of the raw soot sample is so high to depress almost completely the growth of the probe plant. This agrees with the situation observed in the field and described in the Introduction section according to which the few wild plants able to grow in the soot-contaminated site never extend their roots below the upper $1-2 \mathrm{~cm}$ of the soil, where few humic substances and other less toxic components have been accumulated over the aged waste. The growth index is practically null at time zero, that is after the initial mixing between the soot and the active mass, but increases dramatically after 30 days of treatment for the most diluted sample $\left(75 \mathrm{mg} \mathrm{L}^{-1}\right)$ and after 60 days for the more concentrated one $\left(150 \mathrm{mg} \mathrm{L}^{-1}\right)$. The PI tends to a maximum value of $170-210 \%$ after 60 days of treatment, independently on the dilution of the sample, so indicating a significant detoxification of the samples. These results are similar to the decrease in toxicity (checked by the Microtox ${ }^{\circledR}$ bioassay) reported in the literature for the case of soil samples spiked with PAHs and treated with spent mushrooms compost [17].

Concerning the respiration assay (Fig. 3 and last column on Table 4), the AM substrate showed a very high activity (RI > $2000 \mathrm{mg}(\mathrm{kg} \mathrm{VS})^{-1} \mathrm{~h}^{-1}$ ) which, at the beginning, was seriously affected by the addition of $\mathrm{S}$. The oxygen consumption re-started to be significant only after day 30th. All these evidences indicate a growing biological activity on the $\mathrm{S}+\mathrm{AM}$ at day 30 th after the initial mixing which parallels a decrease in the phytotoxicity of the sample.

\subsection{PAHs biodegradation}

The absence of PAHs in the mixture of sewage sludge and yard waste, from which the active mass was obtained, indicated that the amount of PAHs measured during the tests came only from the soot component of the total mass. Time courses for the degradation for the sum of the 16 US-EPA PAHs and for some selected compounds are shown in Fig. 4. Degradation values are given as percent decreases with respect to the concentration measured in the $\mathrm{AM}+\mathrm{S}$ mixture soon after the

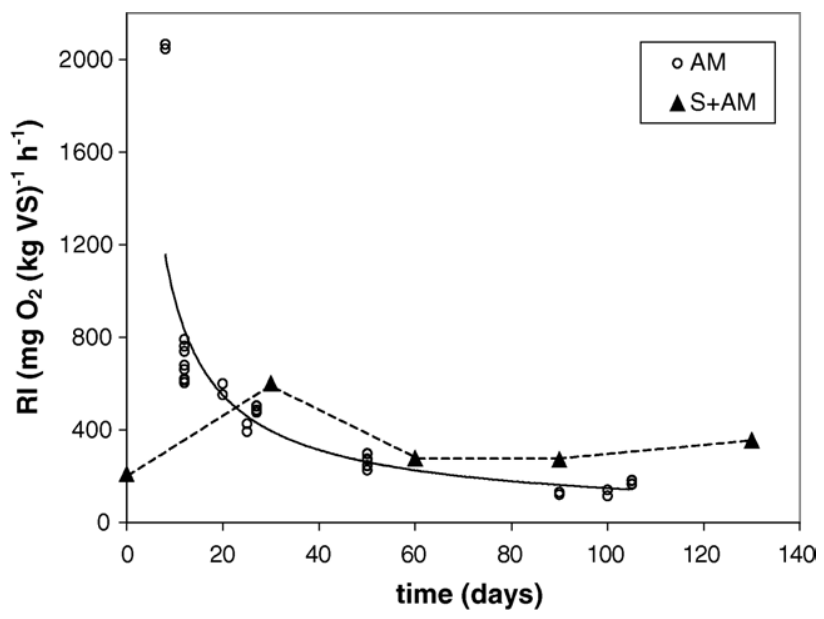

Fig. 3. Time evolution of the respiration index (RI) for the active mass (AM) and active mass added with soot $(\mathrm{AM}+\mathrm{S})$ during the composting treatment. The continuous line is the interpolation of the results obtained on the AM matrix.

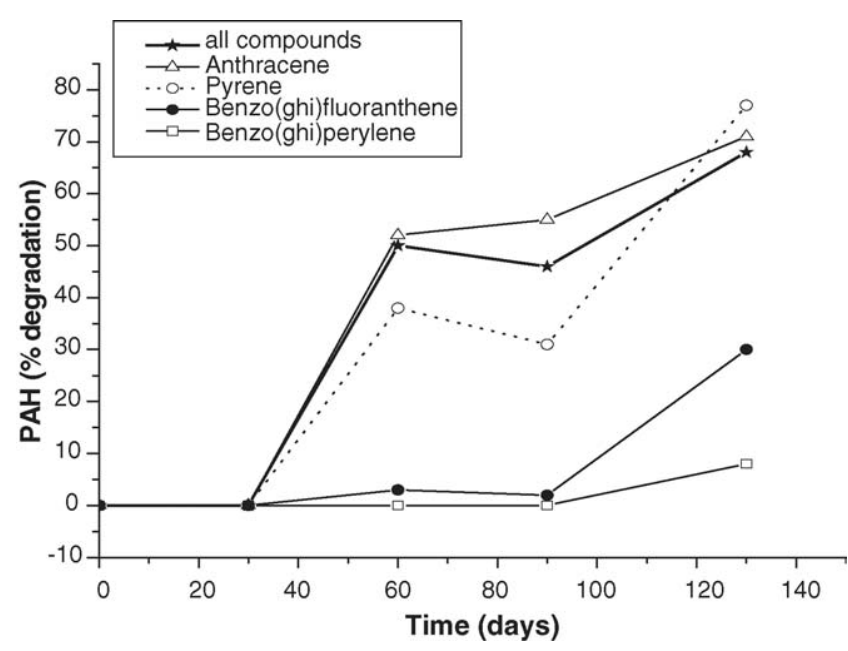

Fig. 4. Time courses for PAHs degradation during the composting treatment. 
initial mixing (day 0 ), taken as value $0 \%$ for the degradation. This in order to take into account also the initial dilution effect related to the addition of the active mass to the soot. As far as the overall cumulative degradation of 16 US-EPA PAHs is concerned, it starts to be significant sometime between day 30 th and 60th to proceed efficiently after day 60th. This trend agrees with the trends observed for the time evolution of $\mathrm{pH}$, EC, temperature and decrease in phytotoxicity which indicated that during the first 30-45 days, the biological activity of the AM re-started after being initially blocked by the addition of S. What is relevant to our goal is that with microbial activity, after the first month started also the PAHs degradation process.

PAHs analyses at day 60th gave an overall degradation in the total content of 16 US-EPA PAHs of about $50 \%$ which increased to $68 \%$ after 130 days. Really, the decrease in the content of "light" $\mathrm{PAH}$ (2-4 rings), such as anthracene $\left(\mathrm{C}_{14} \mathrm{H}_{10}\right)$, starts earlier, probably also because of volatilisation effects. The degradation of relatively "heavy" compounds (5-6 rings), such as pyrene $\left(\mathrm{C}_{16} \mathrm{H}_{10}\right)$, followed the increase in microbial activity, starting slightly later. On the other hand, heavier PAHs such as benzo(ghi)fluoranthene $\left(\mathrm{C}_{18} \mathrm{H}_{10}\right)$ (a non-US-EPA PAH) showed a slower degradation with a maximum of $30 \%$ after 130 days, or benzo(ghi)perylene $\left(\mathrm{C}_{22} \mathrm{H}_{12}\right)$ which are degraded to a very small extent.

The selectivity in degradation observed for the present composting treatment follows the order usually encountered during PAH biodegradation [11,29], with more effective degradation of lower molecular weight compounds.

\section{Conclusions}

The composting process applied to a soot-contaminated soil characterized by a very high $\mathrm{pH}$ showed the capability to promote a slow but effective $\mathrm{pH}$ neutralisation process which promoted microbial activity with concomitant progressive decrease in the PAHs content. Such a lowering in the PAHs content can be attributed mainly to biodegradation by micro-organisms able to degrade the soot. Even if the influence of volatilisation of lighter PAHs, related to the increase in temperature produced during the composting process cannot be excluded, the convergence of the trends observed for physico-chemical parameters (temperature, $\mathrm{pH}$, EC), lowering of phytotoxicity and the decrease in PAHs content excludes a significant role for other abiotic phenomena.

The present achievements appear useful for future progresses in the composting treatment of alkaline soils heavily contaminated by PAHs. The reduction of $70 \%$ in total PAHs obtained with a 130 days of treatment would still leave the PAHs content in the soil at around 50 ppm, which is considerably higher than the $10 \mathrm{ppm}$ required by Italian regulatory guidelines for residential use. However, this value is compatible with the values required for industrial or commercial use $(<100 \mathrm{ppm})$, which are the possible uses expected for this particular site localised inside the industrial area of Porto Marghera.

\section{Acknowledgements}

We dedicate this work to the memory of late Dr. Erminio Chiozzotto, who strongly encouraged this work. Collaboration by Prof. M.C. Gennaro (Università del Piemonte Orientale), Dr. D. Cam and Dr. T. Campisi (CRSA-Fenice), Mr. D. Rudello, Dr. P. Scopece, Dr. S. Zampieri, Dr. D. Tagliapietra and Prof. G. Sburlino (University of Venice), Dr. M. Pazzi (University of Torino) is gratefully acknowledged. Many thanks to Comune di Venezia (Assessorato Ecologia and Settore Lavori Pubblici-Mestre) for providing accessibility to the study site. Partial financial support by the Italian Ministry for the University and Scientific Research (MIUR) is acknowledged.

\section{References}

[1] A. Bispo, M.J. Jourdain, M. Jauzein, Toxicity and genotoxicity of industrial soils polluted by polycyclic aromatic hydrocarbons (PAHs), Org. Geochem. 30 (1999) 947-952.

[2] S. Boonchan, M.L. Britz, G.A. Stanley, Degradation and mineralization of high-molecular-weight polycyclic aromatic hydrocarbons by defined fungal-bacterial cocultures, Appl. Environ. Microbiol. 66 (2000) 1007-1019.

[3] M. Kastner, M. Breuer-Jammali, B. Mahro, Impact of inoculation protocols, salinity, and $\mathrm{pH}$ on the degradation of polycyclic aromatic hydrocarbons (PAHs) and survival of PAH-degrading bacteria introduced into soil, Appl. Environ. Microbiol. 64 (1998) 359367.

[4] F. Haeseler, D. Blanchett, V. Bruel, J.P. Vandecasteele, Ecotoxicological assessment of soil of formed manufactured gas plant site: bioremediation potential and pollutant mobility, Environ. Sci. Technol. 33 (1999) 4379-4384.

[5] B. Antizar-Ladislao, J. Lopez-Real, A.J. Beck, Bioremediation of polycyclic aromatic hydrocarbon (PAH)-contaminated waste using composting approaches, Crit. Rev. Environ. Sci. Technol. 34 (2004) 249-289.

[6] Decreto Ministeriale n. 471/99 Regolamento recante criteri, procedure e modalità per la messa in sicurezza, la bonifica e il rispristino ambientale dei siti inquinati, ai sensi dell'art. 17 del DL 5/2/97 n. 22 e successive modificazioni ed integrazioni, 1999.

[7] G. Caniatto, E. Turri, M. Zanetti, La Laguna di Venezia, Cierre Edizioni, Verona, Italy, 1995.

[8] S.C. Wilson, K.C. Jones, Bioremediation of soil contaminated with polynuclear aromatic hydrocarbons (PAHs): a review, Environ. Pollut. 81 (1993) 229-249.

[9] T.F. Guerin, Bioremediation of phenols and polycyclic aromatic hydrocarbons in creosote contaminated soils using ex-situ land treatment, J. Hazard. Mater. 65 (1999) 305-315.

[10] G.D. Breedveld, M. Sparrevik, Nutrient-limited biodegradation of PAHs in various soil strata at a creosote contaminated site, Biodegradation 11 (2000) 391-399.

[11] S.L. Crawford, G.E. Johnson, F.E. Goetz, The potential for bioremediation of soils containing PAHs by composting, Compos. Sci. Util. Summer 1993 (1993) 41-47.

[12] L.A. Launen, V.H. Buggs, M.E. Eastep, R.C. Enriquez, J.W. Leonard, M.J. Blaylock, J.-W. Huang, M.M. Haggblom, Bioremediation 
of polyaromatic hydrocarbon-contaminated sediments in aerated bioslurry reactors, Biorem. J. 6 (2002) 125-141.

[13] F. Tatàno, Rassegna delle tecniche di risanamento dei terreni contaminati, C.I.P.A. Milano, Lecce, Italy, 1999.

[14] N. Beaudin, R.F. Caron, R. Legros, J. Ramsay, B. Ramsay, Identification of the key factors affecting composting of a weathered hydrocarbon-contaminated soil, Biodegradation 10 (1999) 127-133.

[15] T.F. Guerin, The differential removal of aged polycyclic aromatic hydrocarbons from soil during bioremediation, Environ. Sci. Pollut. R7 (2000) 19-26.

[16] T.S. Brodkorb, R.L. Legge, Enhanced biodegradation of phenantrene in oil tar-contaminated soils supplemented with Phanerochaete chrysosporium, Appl. Environ. Microbiol. 58 (1992) 3117-3121

[17] K.L. Lau, Y.Y. Tsang, S.W. Chin, Use of spent mushroom compost to bioremediate PAH contaminated samples, Chemosphere 52 (2003) 1539-1546.

[18] K.T. Semple, B.J. Reid, T.R. Fermor, Impact of composting strategies on the treatment of soils contaminated with organic pollutants, Environ. Pollut. 112 (2001) 269-283.

[19] T. Cajthaml, M. Bhatt, V. Sasek, V. Mateju, Bioremediation of PAHcontaminated soil by composting: a case study, Folia Microbiol. 47 (2002) 696-700.

[20] B. Antizar-Ladislao, J. Lopez-Real, A.J. Beck, Laboratory studies of the remediation of polycyclic aromatic hydrocarbon contaminated soil by in-vessel composting, Waste Manage. 25 (2005) 281-289.

[21] B. Antizar-Ladislao, J. Lopez-Real, A.J. Beck, In-vessel compostingbioremediation of aged coal tar soil: effect of temperature and soil/green waste amendment ratio, Environ. Int. 31 (2005) 173178

[22] C.J. Carlstrom, O.H. Tuovinen, Mineralization of phenanthrene and fluoranthene in yardwaste compost, Environ. Pollut. 124 (2003) $81-91$.

[23] M.J. McFarland, X.J. Qiu, Removal of benzo(a)pyrene in soil composting systems amended with the white rot fungus Phanerochaete, J. Hazard. Mater. 42 (1995) 61-70.

[24] R.T. Haug, The practical handbook of compost engineering, Lewis Publishers, Boca Raton, Florida, 1993.

[25] UNI10780, Compost. Classificazione, requisiti e modalità di impiego, 1rst, Milano, 1998.

[26] E. Epstein, The Science of Composting, Technomic Publishing Company Inc., Lancaster, PA 17604, U.S.A., 1997, pp. 19-52.

[27] C.H. Collins, P.M. Lyne, J.M. Grange, Collyns and Lyne's Microbiological Methods, sixth ed., Butterworth \& Co. (Publishers) Ltd, Oxford, UK, 1989.

[28] S. Silvestri, L. Dallago, V. Guzzo, L. Paradisi, G. Andreottola, P. Giandon, G. Zorzi, Development of methods for static and dynamic respirometry to assess compost stability, in: T.H. Christensen, R. Cossu, R. Stegmann (Eds.), Proceedings of Sardinia 2003, Ninth International Waste Management and Landfill Symposium. S.Margherita di Pula, Cagliari, 2003, CD-ROM.

[29] C.L. Potter, J.A. Glaser, L.W. Chang, J.H. Meier, M.A. Dosani, R.F. Herrmann, Degradation of polynuclear aromatic hydrocarbons under bench-scale compost conditions, Environ. Sci. Technol. 33 (1999) $1717-1725$ 